\title{
EL TRUHÁN Y SUS APODOS
}

...apode el truhán, juegue de manos y voltee el histrión, rebuzne el pícaro, imite el canto de los pájaros y los diversos gestos y acciones de los animales y los hombres el hombre bajo que se hubiere dado a ello, y no lo quiera hacer el hombre principal, a quien ninguna habilidad déstas le puede dar crédito, ni nombre honroso.

Cervantes, El coloquio de los perros

Los malabarismos verbales de la Crónica burlesca de don Francés han sido parangonados modernamente con los juegos conceptistas de Quevedo y otros escritores del Barroco ${ }^{1}$. Los apuntes que siguen representan una investigación de las raíces históricas de estos paralelos. Un fragmento de la Elocuencia española en arte, de Jiménez Patón, ofrece una excelente vía de acceso a los problemas que me propongo examinar. Me refiero a las consideraciones en que entra al explicar, muy poco después de haber dado comienzo al capítulo sobre el tropo metáfora, por qué integra en él el examen de la catacresis:

Hasta ahora todos hacían distinto tropo la catacresis, no debiendo hacerlo porque llanamente es metáfora, como consta del mismo Cicerón en el libro tercero de su Orador: donde dice que si la metáfora fuere dura se dirá catacresis $[\ldots]$ En castellano parecerá que usa-

1 Véase, por ejemplo, lo dicho por Diana Pamp en su Introducción a Don Francés de ZúÑiga, Crónica burlesca del emperador Carlos V, Crítica, Barcelona, 1981, p. 54. Las citas ulteriores del texto de don Francés remiten a esta edición. 
mos de este tropo, y es poco menos usado que el recto que llamamos metáfora, porque lo es, aunque bastardo. En este tropo están todas las locuciones que decimos apodos, de los cuales podrán ver ejemplos bastantes en la Floresta española y en lo que se refiere de dichos de truhanes, como viendo uno a un cardenal pequeñito, "éste -dijo- no es cardenal, sino burujón", llamar a los estribos de las murallas bestiones, y finalmente otros muchos que no corra muy acomodadamente el símil es catacresis, que como he advertido no es otra cosa sino metáfora dura o bastarda, que por eso los latinos la llamaron abusión².

Es, según veremos, de gran interés la sugerencia de que entran todos los apodos en la categoría de las metáforas "duras" o "bastardas", que suponen que "no corra muy acomodadamente el símil". Pero dejando esto de momento aparte, destacaré la importancia de las referencias de conjunto que en seguida se hacen, a propósito de los apodos, a la famosa recopilación de Melchor de Santa Cruz, y también el interés de la transición que establece una conexión entre los apodos y los "dichos de truhanes". Como tal vez recuerda el lector, dos capítulos de la Floresta se titulan en efecto respectivamente "De apodos" y "De truhanes"; otro capítulo se dedica, por otra parte, a los apodos "de algunos pueblos de España y de otras naciones"3. No quiero decir con esto que las alusiones de Jiménez Patón no se refieran más que a estos tres capítulos; basta, para convencerse de lo contrario, observar que el chiste citado por él a título de ejemplo no está sacado de ninguno de ellos, sino de "De cardenales"' 4 . Pero incluso teniendo en cuenta algo que está manifiestamente conectado con el problema global de los criterios de selección y clasificación seguidos por Santa Cruz, puede darse por seguro que al mencionar expresamente, en forma genérica, los apodos y los dichos de truhanes está pensando Jiménez Patón en particular en los que recogen las secciones así tituladas. Hipótesis que, no obstante, no aclara el porqué de la relación que no menos manifiestamente existe a sus ojos entre las anécdotas y los chistes de estos dos capítulos.

Si nos fijamos, en efecto, en los veinticinco que recoge el capítulo "De apodos", vemos que sólo dos de ellos se atribuyen a

2 E. Casas, La retórica en España, Editora Nacional, Madrid, 1980, pp. 259-260. He modernizado la ortografía de los textos citados en el presente trabajo.

${ }^{3}$ Floresta, II, v ("De truhanes"); VII, II ("De apodos"); IX, vI ("De apodos de algunos pueblos de España y de otras naciones"). La edición que se cita aquí es la de la Sociedad de Bibliófilos Españoles, Madrid, 1953.

4 Ibid., I, II, 15; p. 21. 
un truhán (en este caso, el famoso don Francés). Los ocho primeros se atribuyen a Alonso Carrillo; seis más son de Alonso de Aguilar; cuatro, de un "canónigo de la santa Iglesia de Toledo que se llamaba Diego López de Ayala", atribuyéndose por fin la paternidad del penúltimo dicho de esta breve antología a don Diego de Mendoza, conde de Mélito. En tres de los cuatro casos en que no se especifica el nombre de apodador", se indica que éste es "un caballero" o "un caballero de este reino". Sólo en un caso - que corresponde al caso perfectamente codificado, según veremos, de empleo de apodo para mofarse de la librea de un justador- ignoramos quién es el autor del dicho satírico ${ }^{6}$. Aunque los apodos de pueblos y naciones no tienen, según también veremos, las mismas particularidades que los que están inspirados por la traza de una persona o por la forma de un objeto, el examen de los once que recoge la Floresta podría llevar a una conclusión similar: tres de ellos se asignan al ya mencionado Alonso Carrillo, en dos casos es la apodadora la misma reina Isabel, y don Francés también aparece allí citado dos veces, con dichos sobre Medina del Campo y sobre Segovia. La razón por la que habla Jiménez Patón de los dichos de truhanes, luego de haberse referido a los apodos que, según acabamos de ver, corresponden en su gran mayoría a dichos de personas distinguidas e incluso ilustrísimas, no puede estribar, por lo tanto, más que en las particularidades de los chistes así designados.

La tendencia a igualar a nobles y a bufones, por poco que se toque el tema de los apodos, que se observa según acabo de mostrar a nivel teórico en el texto de Jiménez Patón, también se manifiesta en él a nivel muy práctico de la versión aligerada que éste nos da de un chiste de la Floresta. Como difícilmente será por obra de una mera coincidencia que el mismo chiste ya esté relacionado con un intento de clasificación retórica de los apodos en la Philosophia antigua poética, ofrezco a continuación la versión mucho más conforme al original de López Pinciano, para que se aprecien las divergencias:

${ }^{5}$ Tomo esta palabra, que en el Diccionario de Autoridades no está apoyada con la autoridad de ningún autor conocido, de J. HUarte de SAN JUAN, Examen de ingenios para las ciencias, ed. Rodrigo Sanz, Impr. La Rafa, Madrid, 1930, t. 2, pp. 202-203.

6 "Salió en unas justas un caballero vestido de luto y por la ropa sembrados unos huesos de muertos. A uno que apodó que parecían majaderos, respondió un criado del caballero: "Si lo fueran, vos estuviérades allí' ", Floresta, VII, II, 25; p. 21. 
Y del disímil, como lo dijo don Diego de Mendoza de un Cardenal Legado al Emperador, el cual Cardenal era muy pequeño y muy gordo, y dijo don Diego: "que más parecía chichón que cardenal". Y deste disímil y del símil, jugando del equívoco, se harán mil formas de mover a risa, y, especialmente, en castellano, porque abunda de más equívocos que otra nación, así como el griego de metafóricos; en el símil se pueden poner todos los que decimos apodos, los cuales por tomarse de muchas partes, son también innúmeros $[\ldots]^{7}$.

Es cierto que pueden subsistir dudas acerca de si la versión aligerada del chiste sólo está destinada a ilustrar, en la intención de Jiménez Patón, las consideraciones acerca de los "dichos de truhanes", o si se extiende la ilustración a lo que antes quedó dicho de los apodos. Todo depende de cómo se interprete la coordinación que se establece mediante empleo de la conjunción y, entre la sentencia que se refiere a los apodos y la que se refiere a los dichos de truhanes, pudiendo leerse ésta como mero inciso (en cuyo caso es preciso ponerla entre comas). En la medida en que el orden seguido por Jiménez Patón parece reproducir con gran fidelidad el orden en que se le presentan sus ideas, la estructura de la oración compleja inclina a dar por más lógica la segunda hipótesis. Lo que da a entender esta transición es que existen puntos de contacto entre los chistes atribuidos en su mayor parte a grandes señores y los dichos de los bufones; y esto, que la transición da a entender a nivel teórico, está ilustrado al nivel práctico del chiste sobre el cardenal burujón (o chichón) por la omisión de toda localización concreta del chiste y por el olvido revelador del nombre prestigioso de su autor ${ }^{8}$.

Si nos trasladamos ahora a la época a la que remiten los chistes de la Floresta, veremos que los primeros textos en que apodar significa "usar de una comparación festiva a propósito de una per-

${ }^{7}$ Ed. A. Carballo Picazo, $2^{\text {a }}$ ed., C.S.I.C., Madrid, 1973, t. 3, p. 49. El comienzo del fragmento, ligeramente incoherente tal como aparece aquí citado, ha de leerse a la luz de lo dicho por Fadrique más arriba: "De los conjugatos se tomará aquello de Ovidio".

${ }^{8}$ Lo excepcional no es aquí el cambio de atribución: M. Chevalier ha llamado la atención sobre el hecho de que el chiste atribuido en un lugar a un bufón se pone, en otro, en boca de un caballero. Véase Cuentecillos tradicionales en la España del Siglo de Oro, Gredos, Madrid, 1975, p. 32, n. 38. Yo misma cito más adelante el caso de un chiste de don Francés atribuido por Espinel a Marcos de Obregón. Pero el proceso que desemboca en estas substituciones suele escapar a nuestra atención. Lo peculiar del texto de Jiménez Patón es que ofrece juntamente el modelo teórico y su aplicación. 
sona" confirman que, por lo menos en cierta época, constituyeron los apodos un terreno igualmente cultivado por los nobles y por los bufones. Aunque la fecha en que se publica la versión española del Cortesano es ligeramente posterior a los años en que fue redactada, según hoy se sabe, la Crónica de don Francés ${ }^{9}$, ésta no se examinará aquí más que en segundo lugar. Además de ser en efecto anterior a la Crónica el texto del original italiano vertido al castellano por Boscán, es mucha la luz que proyecta sobre costumbres festivas comunes, según parece, dentro de los círculos aristocráticos de muchos países de la Europa renacentista y cuya huella se advierte claramente en el texto paródico de don Francés. Las comparaciones de tipo prearcimboldesco, que hoy nos parecen un rasgo distintivo del bufón de Carlos V, se describen en efecto en el famoso tratado de Castiglione por boca de Bernardo Bibiena, con palabras que muestran que los demás contertulios están perfectamente familiarizados con ellas:

Las comparaciones también y apodaduras hartas veces tienen gracia y hacen reír, como lo que escribió nuestro Pistoya al Serafín: Tórname a enviar el maletón que te parece; porque, si bien os acordáis, Serafín tenía propio talle de maleta. Hay asimismo algunos que huelgan de apodar hombres y mujeres, a caballos, a perros, a aves, a casas, a carros y a semejantes disparates, lo cual algunas veces parece bien, otras es una muy gran frialdad $[\ldots]^{10}$.

Boscán también reconoce allí algo que le es familiar; por eso, en lugar de limitarse a traducir literalmente comparazioni y comparar, acude a soluciones que revelan que si el sustantivo apodo no es, al parecer, de uso corriente todavía hacia 1530 , un castellanohablante de la época identifica con facilidad los juegos verbales descritos por Castiglione y se da cuenta de que corresponden a lo que él designa con empleos o con derivados del verbo apodar ${ }^{11}$.

${ }^{9}$ Véase a este propósito la Introducción de D. Pamp, p. 62.

${ }^{10} \mathrm{~J}$. Boscán, Los quatro libros del Cortesano compuestos en italiano por el conde Balthasar Castellón y agora nuevamente traduzidos en lengua castellana, ed. M. Menéndez y Pelayo, C.S.I.C., Madrid, 1942, p. 187.

11 Como podrá apreciar el lector confrontando el fragmento que se acaba de citar con el texto original: "Ma ridesi ancora spesso delle comparazioni, come scrisse il nostro Pistoia a Serafino: 'Rimanda il valigion che t'assimiglia', che, se ben vi ricordate, Serafino s'assimigliava molto ad una valigia. Sono ancora alcuni che si dilettano di comparar omini e donne a cavalli, a cani, ad uccelli e spesso a casse, a scanni, a carri, a candeglieri; il che talor ha grazia, talor é freddissmo...", B. Castiglione, Opere..., ed. C. Cordié, Millan-Napoli, 1960, p. 169. 
También se observa que si los ejemplos de comparaciones entre seres humanos y animales son exactamente los mismos en ambos textos, se ha reducido en la versión castellana el número de objetos presentados como posibles términos de comparación; las reservas ante los excesos ocasionados por la invención de símiles "que no corran muy acomodadamente", según decía Jiménez Patón, son, pues, más fuertes en esta versión que en un original en que sólo se advierte que por caer estas comparaciones bien unas veces, y otras mal, ha de considerarse al hacerse uso de ellas "el lugar, el tiempo, las personas". Aflora esta antipatía de Boscán en la frase en que las apodaduras se califican de disparates.

La actitud de don Francés se sitúa, como era de suponer, en el otro extremo, de adhesión y no de rechazo ante las posibilidades abiertas por las comparaciones más descabelladas. Él mismo da a entender, con empleos ocasionales del verbo apodar, que tiene conciencia de ejercitarse en un terreno en que indudablemente era un experto, pero que estaba por otra parte perfectamente codificado ${ }^{12}$. Lo que, al parecer, es propio de él es el uso masivo de los apodos, a modo de contrapunto demoledor, en una "crónica" que se convierte a veces en un centón o en una letanía de comparaciones festivas:

de Toledo [...] al mariscal Fernán Díaz de Ribadeneira, que parecía zamarro viejo de Blas Caballero, canónigo de Toledo; de Avila, a don Pedro de Ávila, que parecía alcotán nuevo o seis maravedís de trementina colada, y Diego Rodríguez de Ávila, que parecía rana pisada, o cucarro del alcornoque; de Valladolid el comendador Santisteban, parlador in magna cantitate, parecía mortero de barro por cocer, y a Juan Rodríguez de Baeza, que parecía contador y secretario del adelantado de Canaria (que Dios haya), o acémila de embajador de Florencia [... $]^{13}$.

Pero incluso cuando se vale de este modo de los apodos, con-

12 Véanse tres muestras de uso de apodar en don Francés, a cuyo propósito se observará que, cuando está mencionado el apodo, el verbo no se emplea seguido de la preposición a, como en Boscán, ni del adverbio como (caso ilustrado por el primer ejemplo citado en el Dice. Aut., s.v. Apodar), sino de una construcción complementaria con parecer que corresponde a la que encontramos en la Floresta: (a) "Esta doña María fue apodada por el ilustrísimo coronista que parecía mula de los atabales de Guadalupe"; (b) "Estos caballeros que iban con el conde, de Extremadura, el autor no los osó apodar, porque fue informado que daban espaldarazos que quitaban la habla"; (c) "como don García de Córdoba, que por servicio deste Emperador salió un día de San Juan vestido de azul, y apodado (sic) por este coronista que parecía palomo cocido untado con cardenillo", ed. cit., respectivamente pp. 115, 123 y 130.

${ }^{13}$ Ibid., pp. 95-96. 
virtiéndoles en instrumentos básicos de su parodia, podemos preguntarnos hasta dónde se extiende el margen de creatividad del famoso bufón. Vemos en efecto que el mismo papel de contrapunto demoledor que en el contexto burlescamente solemne de su crónica asigna éste a los apodos era el que corrientemente se les asignaba en el contexto realmente solemne de las justas. Se comprende que estos momentos de excepcional atención a la presencia física de los justadores y a sus libreas crearan condiciones que también eran excepcionales para los que, como los buenos apodadores, estaban acostumbrados a fijarse sintéticamente en las particularidades físicas y en la indumentaria de quienes tomaban por blanco de su puntería. Está claro, además, que el contraste entre la solemnidad de la fiesta y lo burlesco de los comentarios no podía ser sino muy del gusto de cortes en que sabemos que estos efectos de contraste se cultivaron, aunque en momentos y en condiciones rigurosamente acotados, para servir de alivio al peso agobiante de la etiqueta y a la severidad de las normas que regían la totalidad de la vida social. No insisto en algo que me parece hoy comúnmente admitido, y tampoco me parece útil reproducir aquí una documentación a la que está dedicada una página de la introducción de Diane Pamp ${ }^{14}$. Destacaré, en cambio, que en este contexto específico adquieren los apodos el valor de antimotes caballerescos; es posible que el uso tan ostensible de los apodos en una crónica que en realidad es una anticrónica ${ }^{15}$ esté directamente influido por estos usos anteriores. Son por lo tanto varios los indicios que llevan a la conclusión de que la huella de actitudes festivas o lúdicas propiamente cortesanas es reconocible a cada paso en don Francés, aunque es cierto que su expresión alcanza en él un nivel paroxístico o exacerbado que normalmente puede pensarse que no alcanzaba.

Ya que me interesaba destacar el interés de la relación que cabe establecer entre los comentarios de Castiglione y los apodos al estilo de don Francés, no he tomado en consideración en lo que precede la totalidad del campo abarcado por los apodadores. Su actividad en realidad rebasaba el mero trazo de ingeniosos paralelos entre seres humanos y animales u objetos; era prácticamente universal, según dan a entender unas muestras sacadas de la Floresta, gracias a las cuales vemos que podían apodarse unas tinajas o una cena:

14 Véanse los ejemplos citados en la p. 45.

${ }^{15}$ Según advirtió María Rosa Lida y según confirma D. Pamp en su Introducción, pp. 51-53. 
Pasando la Reina por un lugar, vio en una calle muchas tinajas vacías, medio trastornadas. Preguntó a Alonso Carrillo qué parecían. Respondió: "Frailes que están en gloria Patri".

Don Diego de Mendoza, Conde de Mélito, tenía huéspedes una noche, y fue muy corta la cena. Reprendió a su Maestresala, diciendo: "Ponce, esta cena era buena para espada, porque junta presto la punta con el pomo"16.

Los apodos sobre pueblos y naciones merecen en la Floresta un capítulo aparte, y este tratamiento, como vamos a ver, está plenamente justificado. Sólo algunos de ellos tienen en efecto el mismo carácter chistoso que los que están repertoriados en "De apodos". Observaré de paso que varios de los que tienen este carácter son en cierto sentido divisas al revés o antilemas, exactamente como hemos visto que eran antimotes caballerescos los apodos inspirados por las libreas de los justadores. He aquí dos ejemplos, el segundo de los cuales resulta el más elocuente de los que se pueden aducir, por proponerse en él una etimología festiva del nombre de la ciudad a cuyo propósito se cita:

De Sevilla dijo Alonso Carrillo que parecía a los trabajos de Ajedrez, tanto prietos como blancos, por los muchos esclavos que hay en aquella ciudad.

En la villa de Simancas está esta letra:

$$
\begin{aligned}
& \text { Por librarse de paganos } \\
& \text { las siete doncellas mancas, } \\
& \text { se cortaron sendas manos, } \\
& \text { y las tienen los cristianos, } \\
& \text { por sus armas, en Simancas }{ }^{17} \text {. }
\end{aligned}
$$

Queda de este modo confirmado que los apodos eran con frecuencia aprovechados con fines paródicos, invirtiéndose con su empleo los dichos agudos, sentenciosos o memorables con que procuraban los individuos o las ciudades distinguirse y señalar sus méritos o sus propias excelencias. Pero otros apodos que figuran en el mismo capítulo ya no tienen el mismo aspecto festivo y, lejos de representar una especie de lema burlesco, reproducen con tanta fidelidad la estructura de los lemas tradicionales que parecen destinados a servirles de sustitutos. Esto es lo que ocurre en particular con el primero de los dos dichos atribuidos, al comien-

16 Floresta, VII, II, 3; p. 193 y 24, p. 197.

17 lbid., IX, vi, 5; p. 252 y 8, p. 253. 
zo del capítulo, a la reina Isabel. Éste se inicia, en efecto, con dos dichos de la Reina Católica, ambos sobre Toledo:

De Toledo, decía la Reina doña Isabel, cuando en su presencia alababan otra ciudad: "Si tan grande, no tan fuerte; si tan fuerte, no tan grande".

Alabando el ingenio y habilidad que tenían los desta ciudad, con ser como era de más claro juicio que floreció en su tiempo, decía: "Nunca me hallo necia, sino cuando estoy en Toledo"18.

El segundo de estos dos dichos ha tenido una fortuna singular y ha sido citado y recordado hasta la saciedad. En ningún lugar, en cambio, se recuerda - que yo sepa- que en la Floresta aparece clasificado como apodo. No es difícil dar con la razón de esta clasificación, puesto que a propósito de varios de los dichos sobre pueblos o ciudades está claramente señalado que éstos se alaban o se denigran en comparación con otros. Está esto elocuentemente ilustrado, no sólo por la primera de las dos sentencias de Isabel la Católica sobre Toledo, presentada como réplica a los que "en su presencia alababan otra ciudad', sino por un poema de Juan de Mena sobre Granada, citado por Melchor de Santa Cruz inmediatamente después de los dos dichos de Isabel la Católica:

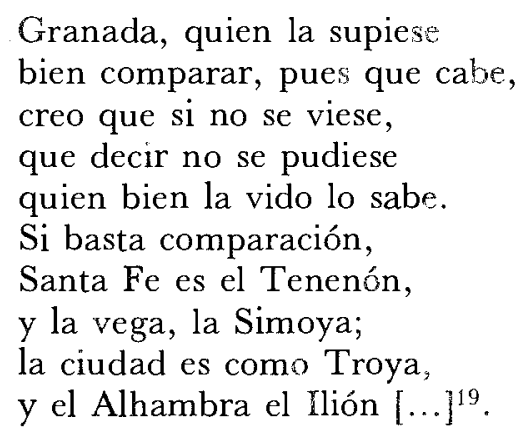

Se observará, por fin, que el último apodo que recoge este capítulo es una de las conocidas y tan repetidas sentencias sobre los méritos y los vicios respectivos de las grandes potencias de la época:

Guando el Cardenal Saviatis vino a España por legado, hallándose en las bodas del Emperador Carlos Quinto, en Sevilla, estando en buena conversación, dijo que Francia le olía a soberbia; y

18 Ibid., IX, vi, 1 y 2 ; p. 251.

${ }^{19}$ Ibid., IX, VI, 3; p. 231. 
España, a malicia; y Italia, a sabios; y Inglaterra, a vanos; y Portugal, a $l o \cos ^{20}$.

Lo que a distancia puede resultarnos desconcertante es que el modelo teórico propuesto por Jiménez Patón, perfectamente adecuado si limitamos nuestro examen a los dichos recogidos en "De apodos", es totalmente inadecuado si lo queremos extender, sin distinción, a todos los apodos del capítulo VI de la novena parte. La dificultad se resuelve si se admite que como el mote, con el que tiene manifiestas afinidades, tiene el apodo dos vertientes, una satírica y otra que no lo $\mathrm{es}^{21}$, distinguiéndose el apodo que no es punzante ni mordaz por el uso de alguna comparación que no siempre supone la presencia explícita de un símil.

No se resuelve tan fácilmente otro problema, que es el de saber si el cultivo de los apodos en sus dos vertientes, atestiguado por la Floresta por lo que se refiere a los reinados de Isabel la Católica y Carlos $V$, es algo que sufre o no evolución en la España de los Felipes. Lo que lleva a plantearlo es, al otro extremo de la trayectoria que aquí se examinará, el tratamiento reservado a los apodos por Gracián. Estamos, con este tratamiento, muy lejos del de la Elocuencia española en arte. Lo primero que destaca Gracián es el carácter de "sutilezas prontas" de los apodos"2. También destaca su parentesco con las "semejanzas conceptuosas", parentesco que en la primera versión de Agudeza y arte de ingenio estaba puesto de relieve, ya que el discurso sobre los apodos venía en ella a continuación de los dedicados a los conceptos por semejanza y por desemejanza, conforme al orden que ya encontramos en la Philosophía antigua poética de López Pinciano. Entre los numerosos ejemplos citados por Gracián, observamos por fin que figura un apodo de ciudad ${ }^{23}$. Pero fuera de este indicio de

${ }^{20}$ Ibid., IX, VI, 11; p. 253.

${ }^{21}$ Me permito remitir, por lo que se refiere al mote, a mi trabajo sobre la burla, La bourle et son interprétation. Espagne, xvi ${ }^{\ell}-x v i i^{\ell}$ siècles, Lille-Toulouse, 1982, pp. 231-236. Tan discreto cortesano como era don Luis Zapata destaca mediante uso de una correlación el parentesco existente entre los motes y las apodaduras: "Los gordos se hacen terrero de graciosos y fisgantes, y son de dichos, de motes y de apodaduras", Memorial Histórico Español, Impr. Nacional, Madrid, 1859, t. 9, p. 65.

22 "Son comúnmente los apodos unas sutilezas prontas, breves relámpagos del ingenio que en una palabra encierran mucha alma de concepto", Agudeza y arte de ingenio, Discurso XLVIII, en B. GRACián, Obras completas, ed. A. del Hoyo, Aguilar, Madrid, 1967, p. 447.

23 "De la gran ciudad de Ormuz se dijo, que 'si el mundo es un anillo, ella es la piedra preciosa", , Ibid., p. 449. 
cierta permanencia, parece haber notables divergencias entre lo que Gracián entiende por apodo y lo que Melchor de Santa Cruz designaba con la misma palabra. Esto se advierte, a nivel muy concreto, confrontando la actitud de Gracián frente a los apodos de la Floresta con la del Pinciano y de Jiménez Patón. Hemos visto que el chiste citado por ellos para ilustrar los comentarios más o menos extensos que dedican respectivamente a los apodos no pertenece al capítulo titulado "De apodos" de la Floresta; ambos preceptistas lo identifican sin embargo como tal, obviamente porque entra sin dificultad en la categoría de las metáforas duras o bastardas a que por otra parte se refiere Jiménez Patón. No puede decirse lo mismo del único dicho de la Floresta que figura en la lista relativamente copiosa de ejemplos presentados por Gracián en el discurso en que trata "De la agudeza en apodos". Ésta se inicia en efecto con un dicho famoso del Gran Capitán, citado por Santa Cruz en De capitanes y soldados:

Desta suerte el Gran Capitán, eminente en este género de donosa prontitud, a un caballero que amaneció muy armado en su caballo, después de una tan sangrienta batalla cuan gloriosa vitoria, dudando los circunstantes quién era, y altercándolo, dijo: "San Telmo, señores, San Telmo"24.

Nada, aquí, recuerda lo que en la terminología de Santa Cruz, luminosa todavía para los preceptistas de comienzos del siglo XVII, se designaba con la palabra apodo. Esta censura de lo mismo que Jiménez Patón consideraba como propio de los apodos es patente en todo el discurso graciane $\mathrm{sco}^{25}$, siendo reveladora la emisión de toda referencia ulterior a los apodos de la Floresta, en un autor que tan excelente conocimiento tiene de la recopilación de Santa Cruz y que tanto gusta de citarla. Tampoco tiene nada

24 Ibid., p. 447. Véase Floresta, II, II, 3; p. 67.

25 Tal vez hayan de exceptuarse dos dichos de Rufo, explícitamente clasificados por Graclán en la categoría de los "apodos satíricos" : "(...) a otro que tenía muchos nombres y renombres [llamó Rufo] don Ledanía; a un hablador muy necio, cascabel de plomo", Agudeza, p. 450. Se observará, sin embargo, que la sequedad misma de Gracián al presentar estos " apodos satíricos" es antiefectista y se opone al relieve que tiene su presentación en otros autores, y que sin duda está en armonía con el virtuosismo propio de estos chistes. Es útil, a este propósito una confrontación entre el "cascabel de plomo" de Rufo, que nos presenta Gracián, y un "cascabel de plata” de don Francés recordado por Luis Zapata: “D. Francés, un hombre muy gracioso, vecino de Béjar, viendo a un caballero muy chico, armado, se llegó a él y le dijo: beso las manos mil veces al cascabel plateado', (cit. por D. PAMP, op. cit., p. 45). 
que ver el empleo de apodar que hace Gracián en el mismo discurso con el que hacían Melchor de Santa Cruz o don Francés; el mero hecho de que pueda decir que la reina Isabel apodó a la hermosura "carta de recomendación, y a la almohada, una sibila muda"26, muestra que la idea de dicho satírico se ha esfumado, pasando al primer plano la agudeza del concepto por semejanza, como en una época anterior ocurría ya, pero únicamente en el caso concreto de apodos sobre ciudades y naciones.

He señalado más arriba que las comparaciones que he llamado prearcimboldescas parecen haber sido enjuiciadas con más reticencias por Boscán que por su modelo italiano. Por valioso que sea este testimonio temprano de recelo ante posibles "disparates", no creo que se pueda comparar con la censura radical de Gracián, cuyos apodos se han expurgado de la "bastardía" que en un momento les llegó a caracterizar. Un cambio tan profundo, y que atañe al significado mismo de palabras cuyo significante no ha cambiado, supone algo más que una reacción personal y posiblemente esté relacionado con la pérdida de prestigio que sufren unos juegos que, según hemos visto, fueron fervorosamente cultivados por eminentes figuras de los reinados anteriores. No significa esto que los caprichos al estilo de Arcimboldo hayan dejado de apreciarse y de servir de modelo en las fiestas cortesanas. Las memorias de don Diego Duque de Estrada nos brindan un excelente ejemplo de la fascinación que siguen ejerciendo hacia $1615^{27}$. Pero parecen haberse desplazado los terrenos en que parece normal que pueda explayarse este gusto por lo irracional. No cabe duda de que en la pérdida de prestigio de una actividad lúdica un tiempo floreciente entre los cortesanos influyeron las posibles confusiones que con motivo del uso de los apodos hemos visto que se creaban entre lo que propiamente podía decir un aristócrata o un eclesiástico y lo que se consideraba como propio de los bufones.

Las etapas por medio de las cuales se llega en los ambientes cortesanos a esta situación de desprestigio de los apodos son difíciles de rastrear. El primer ejemplo que ilustra en el Diccionario de Autoridades el significado del verbo apodar recuerda irresistiblemente los apodos de don Francés ("Elvira Portocarrero salió de

${ }^{26}$ Agudeza, p. 449.

27 "Entré yo a dar la embajada y, después de haber descrito las penas y llantos de Orfeo, formé su cuerpo de una primavera, dando atributos a sus miembros de hortaliza y legumbres (...)", Comentarios del desengaño de sí mismo, ed. H. Ettinghausen, Madrid, 1983, p. 196. La relación con Arcimboldo está señalada en una nota de Ettinghausen. 
blanco, que la apodó Pajarón como escarabajo en leche'). Está sacado de un libro que está escrito a fines del siglo XVI, aunque, por motivos que desconozco, quiere su autor que pase por anterior $^{28}$. ¿Tendría este autor el suficiente dominio de un estilo ligeramente arcaizante como para que podamos pensar que está explícitamente parodiando los apodos cortesanos de comienzos de siglo, o habrá de interpretarse el dicho como mera muestra involuntaria de adhesión a unas modas pretéritas, o como huella esporádica de las mismas?

Otro problema delicado es el de la relación que puede haber entre el progresivo desuso en que caen los apodos al estilo de don Francés en los ambientes cortesanos y el auge de su cultivo entre los estudiantes. El uso de los apodos tales como aparecen definidos por Jiménez Patón forma en efecto parte de la batería de recursos chistosos a la que acuden, a comienzos del siglo XVII, los estudiantes deseosos de poner en aprieto a cualquier contendiente ocasional y en particular a los novatos. El autor de la segunda parte apócrifa del Guzmán nos ha dejado un excelente testimonio de un aspecto de los ritos estudiantiles menos conocido hoy que el famoso y repugnante "bautizo" descrito por Quevedo ${ }^{29}$. Cuando el Guzmán de Martí llega a Alcalá con la intención de proseguir allí sus estudios, está vestido, segun él mismo declara, "como un maltrapillo sucio y ahumado". Sus compañeros, asom" brados de oírle palabras que no conciertan con este traje, se vengan de la sorpresa que les ha dado covirtiéndole en blanco de sus apodos:

empezaron a hacerme apodos, y no era muy difícil el acertar algo en esto, porque yo estaba tal que todo me cuadraba. Parecía ministro de los fuelles de Vulcano, el Faetón tostado, barredero de horno, lavador de cubas, vindimiador de todo el año, danzante sin cascabeles y todo cuanto querían que pareciese parecía ${ }^{30}$.

Doce años después, esta pintoresca sarta de dichos festivamente

${ }^{28}$ No tengo más información acerca de este texto que la que trae el catálogo de la Biblioteca Nacional de París.

${ }^{29}$ Podían los apodos acompañar o preceder al rito bautismal, según da a entender el comentario de uno de los estudiantes que luego interviene en el "bautizo" de Pablos: "Por resucitar está este Lázaro, según hiede". Suárez de Figueroa también se refiere a "cierto gargajeo" luego de haber hablado de los apodos y contraapodos con que se inicia su experiencia en Alcalá (cf. infra).

${ }^{30}$ Mateo Luján, Guzmán de Alfarache, 2a, II, 5, en Valbuena, La nozeta picaresca española, M. Aguilar, Madrid, 1946, pp. 627-628. 
insultantes está reproducida textualmente por un gramático preocupado por la enseñanza del castellano en Francia ${ }^{31}$. No carece este detalle de interés, puesto que si Ambrosio de Salazar sigue, al amenizar sus diálogos escolares con muestras de altercaciones rituales, el ejemplo de autores que han desarrollado con mucho virtuosismo este aspecto de la didáctica posterasmiana, parece ser el primero que para este fin acude a los apodos estudiantiles ${ }^{32}$.

También se refiere a esta faceta de las costumbres estudiantiles Suárez de Figueroa, aportando de este modo una confirmación a lo que decía Martí, aunque sin darnos por su parte ninguna muestra de los apodos y contraapodos mencionados a propósito de su llegada a Alcalá:

Con todo, no me pude librar de algunas matracas; mas habíame en ellas como valiente campeón. De correrme no había que tratar, ni de que por ningún caso me faltasen apodos y contraapodos ${ }^{33}$.

El carácter muy incompleto de mi documentación no me permite aventurar más que hipótesis acerca de si este comportamiento lúdico está arraigado de antiguo entre los estudiantes, o si adoptan ellos los apodos cuando su uso comienza a declinar entre los cortesanos; pero la observación de otros hechos culturales me llevaría a pensar que es más acertada la segunda hipótesis, y que la extensión a los claustros universitarios de actitudes que antes fueron propiamente aristocráticas, pero que en los ambientes cortesanos están cayendo en desuso, forma parte en cierto sentido de su decadencia.

Incluso siguiendo en pie esta incógnita, creo que la doble procedencia de los apodos, cortesana por un lado y por otro escolar, es de gran interés para la comprensión de varios fenómenos literarios. Ha de citarse entre los primeros la caracterización de Justina, presentada desde el comienzo de la obra en que narra su

31 "Y $Y$ es verdad que el trabajo perpetuo es poderoso para vencer naturales muy revesados, yo era de los que floreaban los naipes con pandillas, y rape el diablo lo que hacía a derechas: y con todo eso yo parecía un ministro de los fuelles de Vulcano, el Faetón, tostado como barredero de horno y rodilla de lavar loza, vendimiador de todo el año, danzante en mascarada y sin cascabeles", AmBrosio de SALAZAR, Espexo general de la gramática en diálogos, Rouen, 1614 , pp. 489-490.

32 Estoy pensando, al decir esto, en las pullas que adornan los Pleasant and Delighifull Dialogues de J. Minsheu, cuya versión castellana encontrará el lector en Foulché-Delbosc, "Diálogos de antaño", RHi, 45 (1919).

33 Cristóbal Suárez de Figueroa, El Pasajero, Alivio III, ed. F. Rodríguez Marín, Renacimiento, Madrid, 1913, p. 102. 
vida como "única en dar apodos" "34. El detalle sólo se aprecia plenamente teniendo presente que la confrontación de Justina con estudiantes o medio estudiantes hampones es, junto con la impureza de sus orígenes, el rasgo vital más estable de la pícara, señalándose así claramente la doble filiación de una obra que tanto, o más, tiene que ver con la tradición festiva escolar que con la picaresca alemaniana; aunque también puede pensarse que la excelencia de Justina en el terreno de los apodos es, en parte al menos, una réplica paródica al "muy buen estudiante latino, retórico y griego" engendrado por Alemán.

No encontramos, en efecto, alusión alguna al uso de los apodos estudiantiles en el Guzmán, a pesar de la prolongada estancia del protagonista en Alcalá. Tal actitud, que contrasta con la de autores como Martí, Suárez de Figueroa, López de Úbeda y - según vamos a ver- Vicente Espinel, corresponde a un claro rechazo para la caracterización del pícaro de toda la vertiente disparatada de la tradición chistosa. Guzmán ni siquiera llega a decir apodos cuando sirve en Roma de truhán al cardenal y, luego, al embajador de Francia ${ }^{35}$. Es más radical aún este rechazo que el de Cervantes, quien a pesar de la prevención manifiesta que le inspiran las chocarrerías, pullas, fisgas y matracas sella la caracterización verbal de Vidriera, antes que comience el juego de preguntas y respuestas que luego tiene lugar en las calles de Salamanca, atribuyéndole un dicho que ha de leerse, a mi modo de ver, como un apodo del Licenciado aplicado a su propia persona ${ }^{36}$.

34 "Justina fue mujer de raro ingenio, feliz memoria, amorosa y risuenaa, de buen cuerpo, pelinegra, nariz aguileña y color moreno. De conversación suave, única en dar apodos (...)". Así comienza el "Prólogo sumario de ambos los tomos de La pícara Justina", cito de la edición de A. Rey Hazas, Editora Nacional, Madrid, 1977, t. 1, p. 81.

${ }^{35}$ En Castillo Solórzano, en cambio, un caballero que quiere que un grupo de viajeros le lleve consigo a la Corte, y que con esta intención adopta provisionalmente la máscara de "loco gracioso", ameniza en seguida la primera cena que toma en su compañía diciendo apodos: "Cenaron gustosamente porque en toda la cena no cesó don Pedro de decir donaires y apodos a los circonstantes, con que los tuvo muy entretenidos", La Garduña de Sevilla y el anzuelo de las bolsas, Espasa-Calpe, Madrid, 1972, p. 164.

36 " -- ¿Qué me queréis, muchachos, porfiados como moscas, sucios como chinches, atrevidos como pulgas? ¿Soy yo, por ventura, el monte Testacho de Roma, para que me tiréis tantos tiestos y tejas?", Cervantes, Novelas ejemplares, ed. J. B. Avalle-Arce, Castalia, Madrid, 1982, t. 2, p. 119. Un ejemplo de don Francés muestra que los bufones podían en efecto tomarse como blanco de su propia puntería: "Y luego este coronista don Francés fue armado, y con él el arzobispo de Bari y otros muchos caballeros (...) (Este don Francés parecía, armado, hombrecico del reloj de San Martín de Valdeiglesias, y 
Pero volviendo a los autores cuyo uso de los apodos no puede dar lugar a dudas o a discusiones, en la medida en que está señalado por ellos mismos, me propongo examinar ahora el caso altamente significativo de un dicho de don Francés que cambia, en parte al menos, de sentido al estar citado en la Vida de Marcos de Obregón. Débese este cambio de sentido no a una alteración del chiste, que está reproducido textualmente, sino al contexto en que aparece citado y a cuyo propósito se aplica. Hay en efecto un momento de la vida de Marcos en que éste llega, tras largas y cultas discusiones con un oidor en cuya compañía viaja, a una venta atendida por una ventera que el mozo de mulas les ha presentado de antemano como "muy hermosa y aseada" (es preciso señalar que el narrador indica que esta ventera era conocida del mozo de mulas "más de lo que fuera razón"). Al entrar, descubren los dos viajeros a la huéspeda, que es en realidad "muy boquifruncida" y que, por encima de un vestido colorado oscuro, lleva "una ropa de lienzo blanco llena de picaduras". Comienza entonces el siguiente diálogo, en que Marcos y su compañero se vengan de la decepción que se han llevado:

preguntóme el mozo de mulas: "¿Qué le parece a vuesa merced?" Yo le respondí: "Paréceme asadura con redaño". Y dijo el oidor: "Está vestida de virgen y mártir". "Bien dice vuesa merced —dije yo-; mas está la castidad por de fuera y lo mártir por de dentro, y como hay muchas matas por aquí, está muy rota la castidad". "Cada uno habla como quien es", dijo la ventera.

Volví la hoia, porque la vi corrida del apodo y el mozo de mulas enojado[... $]^{37}$.

El primero de los dos apodos - puesto que a cada interlocutor culto le toca decir el suyo- está sacado de la Floresta, donde es uno de los comentarios de don Francés inspirados por las libreas de los justadores:

La librea deste juego de cañas era de terciopelo leonado, y encima tafetán blanco, muy acuchillado. Preguntó el Emperador a don Francés: "¿Qué te parece de aquella librea?" Respondió: "Asadura con redaño" $" 38$.

el arzobispo de Bari, anguila recién sacada del río, o de rocín con desmayos)" ed. cit., p. 83.

37 Vida del escudero Marcos de Obregón, III, 15, ed. M. Soledad Carrasco Urgoiti, Castalia, Madrid, 1972, t. 2, pp. 216-217.

${ }^{38}$ Floresta, II, v, 4; p. 74. 
Como he dicho, es significativo el salto que se da de los ambientes cortesanos en que se inventan libreas para los juegos de cañas al de una venta cuya dueña está con mucha insistencia presentada de una manera degradada, desempeñando a su propósito el contraste de colores y el detalle de las "picaduras" otro papel que el "terciopelo leonado" y el "tafetán blanco, muy acuchillado" a los que han sustituido. El salto, además, se da de un contexto -el del juego de cañas-, en que formaba parte del rito festivo que se hicieran comentarios chistosos sobre las libreas de los jugadores, a otro, el de la venta, en que también son rituales los intercambios festivos, con la ligera restricción de que lo ritual, al llegar a una venta, era decir y oír pullas, y no apodos. En el episodio del Marcos de Obregón que estoy examinando, el intercambio de pullas tiene lugar cuando termina el diálogo entre los dos viajeros y la ventera, y se deja para dos personajes subalternos (el mozo de mulas y un "muchacho frailesco" que sirve de gracioso durante el viaje, según he mostrado en otro lugar $\left.{ }^{39}\right)$. Vemos de este modo que, a pesar de la degradación reveladora del contexto en que se llegan a decir los apodos, éstos se reservan para los personajes cultos, ingeniosos y que conservan el recuerdo de su estancia en Alcalá o Salamanca.

He dejado para el final a Quevedo, cuyo nombre es el primero que suele citarse a propósito de las comparaciones festivas de don Francés. Dada la importancia que tiene en su caso el modelo retórico de los apodos, me pareció que aquí no era útil acumular ejemplos, pero que en cambio valía la pena dar el largo rodeo que se ha dado en las páginas que preceden para mostrar que un recurso que con tanta prolijidad utiliza en sus obras satírico-festivas le pertenece por ser, como él mismo, escolar y cortesano. Me limitaré a añadir que no parece fortuito que, según señala el Diccionario de Autoridades, le debamos el neologismo apodadero, empleado por él en el Libro de todas las cosas a propósito de los hombres de mucha nariz, detalle que puede sugerir una nueva interpretación e incitar a una nueva lectura de un conocido soneto.

Diré en fin, para terminar, que como los recursos que pueden servir para la caricatura verbal no son infinitos, se ha hablado a veces de don Francés y de Quevedo como de lejanos modelos del Valle-Inclán de los esperpentos. Creo que frente a este problema pueden adoptarse dos actitudes: la de quien está más atento a la permanencia de ciertas actitudes "deshumanizadoras" que al contexto histórico concreto en que nacen, se desarrollan y mueren

39 Véase mi trabajo La bourle et son interprétation..., pp. 464-466. 
formas y expresiones inconfundibles de esta deshumanización y la de los que optan por la solución contraria. Indagando en las raíces que el esperpento tiene en la caricatura del siglo XIX, Iris Zavala ha ilustrado excelentemente la segunda de estas dos actitudes por lo que se refiere a Valle ${ }^{40}$. Con diferente método, ésta es también la línea que aquí he procurado seguir.

Université de Lille III

MONIQUE JOLY

${ }^{40}$ En dos artículos recogidos en El texto en la historia, Nuestra Cultura, Madrid, 1981 ("Del esperpento" y "Notas sobre la caricatura política y el esperpento", pp. 111-117 y 119-129). 